\title{
The effects of MK-801 injections and dorsal cortex lesions on maze learning in turtles (Chrysemys picta)
}

\author{
MICHELLE REIMAN AVIGAN and ALICE SCHADE POWERS \\ St. John's University, Jamaica, New York
}

\begin{abstract}
The present studies examined the effects of dorsal cortex lesions and injections of MK-801, an NMDA receptor blocker, on learning of a position habit in a maze. In Experiment 1, turtles were trained in a T-maze for food reward. After they had mastered this task, the turtles were randomly assigned to three groups: dorsal cortex lesion, MK-801 injection, or sham-lesion/saline-injection control. The animals were run in an X-maze for 40 days or until they reached criterion. In comparison with controls, the lesion and MK-801 groups were significantly impaired in X-maze learning. Experiment 2 examined the effects of MK-801 injections on measures of general activity. These measures were not affected by injections of MK-801. The results provide evidence for the involvement of the turtle dorsal cortex and the NMDA receptor in the acquisition of a position habit.
\end{abstract}

The reptilian brain provides a simple model in which learning and memory can be studied. The dorsal cortex of turtles, a region on the surface of the telencephalon, appears to play a role in associative processes. Damage to the dorsal cortex has been linked to slower habituation (Killackey, Pellmar, \& Ebner, 1972), reversal deficits (Cranney \& Powers, 1983; Grisham \& Powers, 1989, 1990; Peterson, 1980), acquisition deficits in discrimination and operant tasks (Blau \& Powers, 1989; Grisham \& Powers, 1989), and deficits in the retention of maze learning (Petrillo, Ritter, \& Powers, 1994).

Also of recent interest in the investigation of learning and memory has been the connection between long-term potentiation (LTP) and the acquisition of new responses. LTP is a model for change in synaptic activity that may provide the physiological basis for information storage in the brain (Collingridge \& Bliss, 1987). When highfrequency stimulation is applied to certain regions of the brain, LTP is induced. This is a state in which the cells have an enhanced synaptic potential that can last for weeks or even months. This property has made LTP attractive as a model for learning (Bliss \& Lynch, 1988).

Much effort has been focused on elucidating the mechanisms responsible for LTP. It appears that the activation of a membrane channel associated with the $\mathrm{N}$ methyl-D-aspartate (NMDA) receptor is a necessary pre-

This paper includes research submitted by M.R.A. in partial fulfillment of the requirements for the $\mathrm{PhD}$ degree at St. John's University. The research was supported by a University doctoral fellowship to M.R.A. and a St. John's University summer research fellowship to A.S.P. Requests for reprints should be addressed to A. S. Powers, Department of Psychology, St. John's University, 8000 Utopia Parkway, Jamaica, NY 11439. requisite for induction of one type of LTP (Artola \& Singer, 1987). Blockage of the NMDA receptors prevents the induction of this type of LTP in the hippocampus (Artola \& Singer, 1987; Errington, Lynch, \& Bliss, 1987). Once LTP is induced, however, blocking NMDA receptors does not affect its maintenance. If LTP is seen as learning, this suggests that blockage of the NMDA receptor will block learning but will not affect memory. MK-801, a noncompetitive NMDA receptor antagonist, easily crosses the blood-brain barrier and it blocks LTP when injected systemically in mammals (Gilbert \& Mack, 1990).

Since NMDA-receptor-mediated transmission has been demonstrated to be present in the turtle dorsal cortex (Larson-Prior \& Slater, 1988; Young, Sakurai, \& Albin, 1990), and since in vitro studies have shown that LTP is present in both lizard (Larson \& Lynch, 1988) and turtle cortices (A. Kriegstein, personal communication, 1987), it seems possible that NMDA receptors in the turtle dorsal cortex might play a role in learning. This was investigated in the present study by comparing the deficits produced by two experimental manipulations, a dorsal cortex lesion and the injection of an NMDA receptor blocker, MK-801.

Past attempts in this laboratory to investigate the effects of maze acquisition on learning have proved to be problematic, because a relatively large percentage of untreated turtles fail to learn the task. Pilot data suggested that animals that demonstrated the ability to learn a T-maze would reliably learn an X-maze as well. Consequently, only animals that learned a T-maze were included in this experiment. Those animals were then randomly assigned to a dorsal cortex lesion group, an MK-801 injection group, or a sham-lesion/saline-injection control group and trained in an X-maze. 


\section{EXPERIMENT 1 Method}

\section{Subjects}

Seventeen naive Midwestern painted turtles (Chrysemys picta) weighing between 200 and $400 \mathrm{~g}$ were used. The turtles were housed individually in tanks measuring $37 \times 47 \mathrm{~cm}$. Each tank contained water approximately $4 \mathrm{~cm}$ deep as well as a platform for basking. The room in which the animals were housed was kept at a constant temperature of $30^{\circ} \mathrm{C}$, and a 14:10-h light:dark cycle was maintained. The turtles were run during the light part of the cycle.

\section{Apparatus}

Pretraining. The turtles were trained to eat Gerber's beef baby food in a box made of black Plexiglas into which food was automatically delivered. The box, containing water approximately $5 \mathrm{~cm}$ deep, measured $21 \mathrm{~cm}$ deep, $23 \mathrm{~cm}$ long, and $21 \mathrm{~cm}$ wide. The cover, also made of black Plexiglas, had a window, which allowed the experimenter to observe the animal. Mounted on one wall of the chamber was a white disk with an opening in the middle through which the beef baby food was delivered by a syringe pump connected to a rubber tube

Preoperative and predrug training. First, the turtles were trained on a T-maze. The arms of the maze, which were constructed of gray metal, each measured $54 \mathrm{~cm}$ long and $12 \mathrm{~cm}$ wide. The start well and the end wells consisted of white plastic buckets, $28 \mathrm{~cm}$ in diameter, into which a square hole was cut and the arm inserted. The three arms were connected in the center by a larger bucket measuring $35 \mathrm{~cm}$ in diameter. The start and center wells had floors of dry styrofoam. The goal well, reached by making a right turn from the start, and the other end well, reached by making a left turn, were filled with water approximately $3 \mathrm{~cm}$ deep. The goal contained a shelf on which the reinforcement, beef baby food, was found. Taped to the side of the end well of the left arm was a plastic container with a perforated top, full of beef baby food. The food was inaccessible to the animal but served to equate olfactory cues. Food in both end wells was out of sight of the animal from outside the wells. A guillotine door separated the start well from the rest of the maze. A string attached to the door and strung through a pulley on the ceiling allowed the experimenter to raise and lower this door from behind a curtain outside the cubicle in which the maze was located.

Postoperative and drug training. The turtles were then tested in an X-maze. This maze was constructed in much the same way, using the same-sized buckets and alleyways. In the case of the X-maze, however, the goal well could be reached by going straight ahead from the start well and the end wells of the right and left arms both had containers full of food taped to the sides of the buckets. Additionally, the maze was rotated counter clockwise $45^{\circ}$ in the room.

Both mazes were in an experimental cubicle approximately $2 \mathrm{~m}$ long $\times 1.5 \mathrm{~m}$ wide. The cubicle was separated from the laboratory by a curtain to shield the experimenter from the view of the turtle. Extramaze cues-namely, a light blue piece of paper taped to the right wall and a stack of buckets in the right corner-were deliberately provided.

\section{Procedure}

Magazine training. Turtles were first trained to eat in an automated situation in the training chamber described above. Each turtle was placed in the box once per day, 5 days a week, and allowed to eat as food was automatically delivered through the tube on a variable time $60-\mathrm{sec}$ schedule for a total of 20 deliveries per day. Turtles that ate in this situation on 3 successive trial days were chosen for the experiment.

T-maze training. The selected animals were then "trained" to eat in the T-maze. Training involved acclimating the animals to the apparatus and allowing them to learn that this was a place where food would be found. This was accomplished by placing the turtle in the goal well, next to the food, and on successive trials, moving the animal farther and farther away from the food. On each training day, the turtles were given three trials. A turtle was considered to be successfully trained if it walked to the food and ate on two out of three trials on 2 successive days. If a turtle was not successfully trained for several weeks, the animal was placed back into the automated situation and later retrained in the maze. If a second maze training attempt was unsuccessful, the animal was rejected.

After successful training, the animal began the T-maze phase of the experiment. Each animal was given three 5-min trials per day with a 10 -min intertrial interval (ITI). A trial consisted of placing each turtle in the start well of the T-maze with the guillotine door closed. After a l-min recovery period, the door was raised, allowing the turtle free access to the rest of the maze. The animal was allowed to explore the maze until it reached the goal well, at which point the animal was allowed to eat for $15 \mathrm{sec}$ before being returned to its home cage. The turtle was also returned to its home cage if it failed to reach the goal after $5 \mathrm{~min}$. The turtle's course was recorded for each trial, and a daily score was derived by dividing the number of goals reached (maximum number $=3$ ) by the number of alleys entered. For example, if on one day, an animal walked right to the goal well on the first two trials and then made a wrong turn on the third trial and failed to explore further, that day's score was calculated as the number of goals (2) divided by the number of alley entries (3), or .67. An animal reached criterion when it scored .67 or better on 2 successive days. This score meant that the turtle made no more than one incorrect choice on 2 successive days.

Experimental manipulation. Once a turtle had learned the Tmaze, it was randomly assigned to one of three groups: dorsal cortex lesion, MK-801 injection, or sham-lesion/saline-injection control. There were 5 subjects in the lesion group and 6 subjects in each of the MK-801 and control groups.

Turtles in the dorsal cortex lesion group were anesthetized with Equithesin $(.25 \mathrm{ml} / 100 \mathrm{~g}$ injected i.p., just in front of the hindleg), which is a mixture of sodium pentobarbital and chloral hydrate. Using a stereotaxic instrument developed for turtles along with an atlas of the turtle brain (Powers \& Reiner, 1980), the turtle's skull was opened in order to create the dorsal cortex lesion. A piece of the animal's skull was removed and the dorsal cortex aspirated through a pipette. A 5- to 7-day postoperative recovery period was allowed before the turtle was run in the X-maze.

Turtles in the MK-801 group were also given a 5- to 7-day rest period before beginning in the X-maze. Daily subcutaneous injections of MK-801 $(.05 \mathrm{mg} / \mathrm{kg}$ in $.5 \mathrm{ml} / \mathrm{kg}$ saline $)$ were given to these animals, $20 \mathrm{~min}$ before trials in the X-maze were run.

Half the turtles in the control group were given sham lesions. The procedure was identical to that of the lesioned animals, with the exception of the removal of the dorsal cortex. The rest of the controls were given daily subcutaneous saline injections $(0.5 \mathrm{ml} / \mathrm{kg})$ 20 min prior to running in the X-maze. Controls were given the same rest period between T-maze and X-maze training as the other subjects.

X-maze training. After the recovery period, turtles in each of these groups were run in the $\mathrm{X}$-maze. Each animal was again run for three 5 -min trials per day with a 10 -min ITI. Data were collected in the same way as described above, and scores for each day were recorded. All animals were run in the X-maze until they reached criterion. Training was discontinued if an animal failed to learn in 40 days.

Histology. Upon completion of the X-maze, the turtles in the lesioned group were perfused under deep anesthesia with saline followed by Heidenhain's solution (without mercuric chloride). The brains were embedded in paraffin and sectioned at $15 \mu$. The sections were stained with the Kluver-Barrera stain, which stains cells with cresyl violet and axons with luxol fast blue.

The lesions were reconstructed by an investigator blind to the results of the experiment, on plates from the atlas of Powers and 
Reiner (1980). The percentage of damage to the dorsal cortex was calculated separately for each hemisphere.

Statistical analyses. The data collected over the course of the study included the number of entries each subject made per day, score per day, whether or not the animal ate when it reached the goal, days to criterion, and percentage of bilateral damage to the dorsal cortex. Because individual animals perform so differently on maze learning tasks when brain lesions and drugs are introduced, homogeneity of variance, an assumption of all parametric statistical computations, is violated. The data were therefore evaluated by nonparametric statistical techniques.

\section{Results}

\section{Histology}

Each subject's percentage of damage is presented by hemisphere in Table 1. All 5 subjects in the lesion group sustained bilateral damage to the dorsal cortex. No other structure was damaged bilaterally. To determine whether the amount of bilateral tissue damage was related to behavioral deficits, a Spearman rank correlation coefficient was calculated between percent damage and days to criterion. The coefficient calculated revealed a high correlation between mean percent damage and maze learning deficit $(\rho=.84, N=5, .10>p>.05)$.

\section{Transfer from the T-maze to the X-maze}

Although the position of the start well was different during $\mathrm{T}$-maze and $\mathrm{X}$-maze training, the turtles as a whole gave evidence that they remembered the T-maze. Nine out of 17 animals made a right turn (the correct turn in the $\mathrm{T}$-maze) on the first trial in the X-maze. This proportion is significantly different from chance $\left[\chi^{2}(1)=7.08, p<\right.$ $.01]$. Of this number, 4 were in the control group, 2 in the MK-801 group, and 3 in the dorsal cortex group. Although these numbers might suggest that the MK-801 group remembered the previous maze more poorly, other data do not support this hypothesis. In all of Day 1 , the number of turtles in each group that chose the previously correct arm at least once was 5 out of 6 for the control group, 5 out of 6 for the MK-801 group, and 3 out of 5 for the dorsal cortex group. No other choice was made so frequently. Thirty of the 51 first choices made on Day 1 were made to the previously correct arm. No significant differences among the groups in choices on Day 1 were found [Kruskal-Wallis analysis of variance: $\mathrm{KW}(2)=0.85, p>$ $.05]$. Similarly, no significant difference between groups was found in choice of the previously correct arm on the first 5 days of training [Kruskal-Wallis analysis of

Table 1

Percentage of Dorsal Cortex Damage in Lesion Group

\begin{tabular}{ccc}
\hline & \multicolumn{2}{c}{ Hemisphere } \\
\cline { 2 - 3 } Subject & Left & Right \\
\hline 719 & 15 & 9 \\
724 & 3 & 3 \\
726 & 11 & 8 \\
745 & 8 & 11 \\
776 & 17 & 23 \\
\hline
\end{tabular}

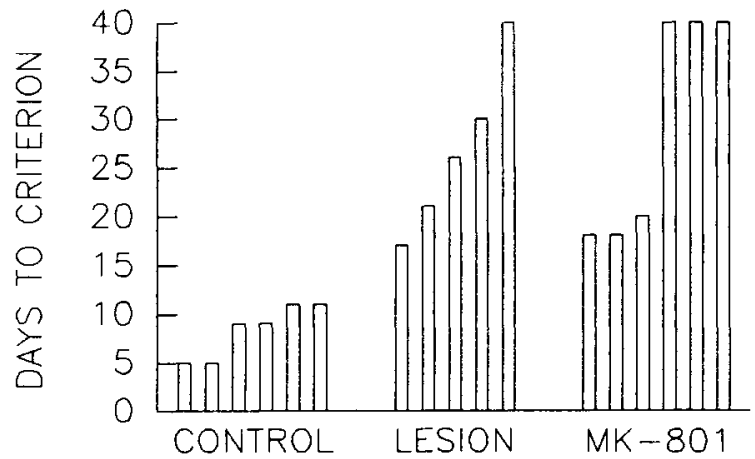

Figure 1. The days to criterion on the $X$-maze for all subjects, arranged by groups.

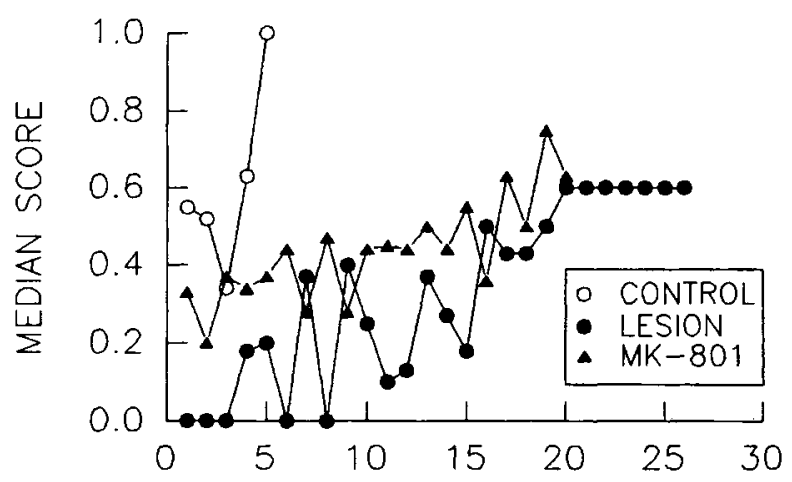

Figure 2. The median scores per day for each group on the $X$-maze. Criterion was a score of .67 for 2 consecutive days. Higher scores reflect better performance.

variance: $\mathrm{KW}(2)=3.46, p>.05]$. The latter finding shows that all groups extinguished their preference for the arm that had been correct in the T-maze at the same rate.

\section{Group Comparisons on Days to Criterion}

Figure 1 presents the data on days to criterion for each animal in the experiment. In comparison with the control group, both experimental groups were impaired. The groups were compared using the Mann-Whitney $U$ test with alpha set at .025 to compensate for multiple comparisons. The lesion group and the MK-801 group were both significantly impaired in maze learning in comparison with controls $(U=0, p<.002$ and $U=0, p<.001$, respectively). The two experimental groups were not different from one another $(U=12, p>.05)$. To demonstrate this impairment further, the median scores per day for each group were plotted. Figure 2 presents median scores per day for each group on the X-maze.

\section{General Activity in the Maze}

Figure 3 presents the median number of alley entries for each group. The numbers of entries in the first 5 days of training were also compared by using the Mann- 


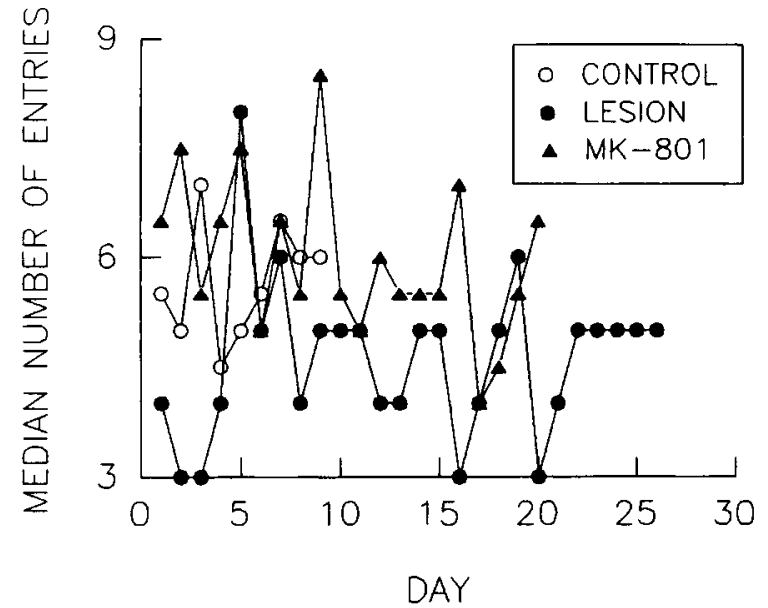

Figure 3. The median number of alley entries per day for each group in the $\mathrm{X}$-maze.

Whitney $U$ test. Results indicated that none of the groups differed significantly from any other with respect to this measure ( $p>.05$ for all comparisons).

\section{EXPERIMENT 2}

In the course of this research, a question arose as to whether MK-801 might be having nonspecific effects on the turtles' behavior. Heale and Harley (1990), for instance, found an increase in activity in rats injected with MK-801. Therefore, the effect of MK-801 on unlearned behavior was investigated in Experiment 2. The dependent measures were activity in an open field and ability and latency of the animals to turn over when placed on their backs.

\section{Method}

\section{Subjects}

Six experimentally naive Midwestern painted turtles (Chrysemys picta) weighing between 200 and $400 \mathrm{~g}$ were used. The animals were housed in the same conditions as described in Experiment 1 .

\section{Apparatus}

For measuring movement in an open field, each turtle was placed in an enclosed area of approximately $1.35 \times .7 \mathrm{~m}$. The area was divided into six squares $(.35 \times .45 \mathrm{~m}$ each $)$ by masking tape markings.

For studying the ability and latency to turn over, the turtles were placed in a standard-sized 3-gal bucket.

\section{Procedure}

Using random assignment, 3 of the 6 animals were injected subcutaneously with $.05 \mathrm{mg} / \mathrm{kg} \mathrm{MK}-801$ (in $.5 \mathrm{ml} / \mathrm{kg}$ ), and the other three with saline $(.5 \mathrm{ml} / \mathrm{kg}) 20 \mathrm{~min}$ prior to testing. In testing activity in an open field, each turtle was allowed to roam freely in the enclosed area described above for two 5-min trials, with an ITI of $10 \mathrm{~min}$. The experimenter remained behind a curtain to observe the animals without being seen. The amount of movement was measured by how many squares the turtle entered, averaged over the two trials.

The turtle's ability to turn over was studied by placing each turtle on its back in the bucket. The latency to turn over was taken, and a score of 1 was given if the turtle succeeded in righting itself. Two 5-min trials with an ITI of 10 min were run; the scores for the day were the total score over the two trials. The investigator again remained out of the sight of the animals.

The procedure described above was repeated 1 week later with the saline group getting MK- 801 and the MK- 801 group receiving a saline injection.

\section{Results}

Table 2 presents the means and standard errors for each test for MK-801 and saline. To compare scores for general activity and turning over, the Wilcoxon matchedpairs test was employed. There were no significant differences between the drug and no-drug conditions on any of the three measures ( $p>.05$ for all comparisons).

\section{DISCUSSION}

In the present study, it has been demonstrated that both dorsal cortex lesions and MK-801 injections can impair learning of a position habit in an X-maze. These findings are consistent with the hypothesis that the dorsal cortex and NMDA receptors play an important role in learning in turtles.

Although the dorsal cortex is known to be involved in a wide variety of learning processes (see Powers, 1990), no previous work has shown a clear relationship between lesions of the dorsal cortex and deficits in the acquisition of a maze habit. Morlock (1972) studied acquisition of a black-white arm discrimination in a T-maze in turtles with dorsal cortex lesions. Although the lesioned animals as a group performed more poorly than controls, statistical comparisons of the two groups were not given. Thus Morlock's study provided only the suggestion of impairment in maze acquisition in animals with dorsal cortex damage.

With the method developed for this experiment, it was possible to examine the effects of lesions and MK-801 on maze acquisition in turtles. This new procedure,

Table 2

Scores on Tests of Unlearned Behavior

\begin{tabular}{|c|c|c|c|c|c|c|}
\hline \multirow[b]{2}{*}{ Condition } & \multicolumn{2}{|c|}{$\begin{array}{c}\text { Movement in } \\
\text { Open Field } \\
\text { (No. Squares Entered) }\end{array}$} & \multicolumn{2}{|c|}{$\begin{array}{c}\text { Ability to } \\
\text { Turn Over } \\
\text { (No. Successes) } \\
\end{array}$} & \multicolumn{2}{|c|}{$\begin{array}{l}\text { Latency to } \\
\text { Turn Over } \\
\text { (Sec) }\end{array}$} \\
\hline & $M$ & $S E M$ & $M$ & $S E M$ & $M$ & $S E M$ \\
\hline MK-801 & 6.0 & \pm 3.09 & 1.17 & \pm 0.37 & 147.5 & \pm 54.76 \\
\hline Saline & 6.0 & \pm 2.58 & 1.0 & \pm 0.41 & 187.17 & \pm 49.77 \\
\hline
\end{tabular}


which allows preselection of turtles that are capable of learning a maze, opens up the study of maze acquisition in these animals to other manipulations as well.

With this method, the present study has shown for the first time evidence that the dorsal cortex is involved in the acquisition of a position habit in a maze. The lesions in this study were small, less than $25 \%$ bilateral damage to the dorsal cortex. Nevertheless, the data suggest that the more damage the dorsal cortex sustained, the longer it took for the animals to learn the task. Thus, this task appears to be very sensitive to damage to the dorsal cortex.

The present method was also well suited for investigating the effects of blocking NMDA receptors. LTP, an activity-dependent change in the synaptic potential, seems best studied through response acquisition, since the blockage of NMDA receptors seems not to affect the maintenance of LTP once the process has been initiated (Errington et al., 1987) - or once the learning has taken place (Heale \& Harley, 1990). Studies have shown that the blockage of NMDA receptors in mammals disrupts early learning in the form of developmental plasticity (Cotman \& Iversen, 1987; Kleinschmidt, Bear, \& Singer, 1987). Adult animals show deficits after blockage of NMDA receptors on such diverse tasks as a nonspatial operant DRL task (Tonkiss, Morris, \& Rawlins, 1988), a passive avoidance task (Venable \& Kelly, 1988), tastepotentiated odor aversion learning (Robinson, Crooks, Shinkman, \& Gallagher, 1989; Willner, Gallagher, Graham, \& Crooks, 1992), fear-potentiated startle responding (Miserendino, Sananes, Melia, \& Davis, 1990), and spatial learning tasks (Heale \& Harley, 1990; Morris, Anderson, Lynch, \& Baudry, 1986; Robinson et al., 1989; Shapiro \& Caramanos, 1990; Shapiro \& O'Connor, 1992). In addition, blockade of NMDA receptors has been shown to disrupt learning in chicks (McCabe, Davey, \& Horn, 1992) and goldfish (Xu \& Davis, 1992).

It has been demonstrated that NMDA-receptor-mediated transmission is present in the turtle dorsal cortex (Larson-Prior \& Slater, 1988; Young et al., 1990), and in vitro studies have shown that LTP is present in both lizard (Larson \& Lynch, 1988) and turtle cortices (A. Kriegstein, personal communication, 1987). In the present study, it was demonstrated that injection of the NMDA receptor blocker MK-801 resulted in a deficit in the turtles' maze learning. This finding is consistent with the hypothesis that NMDA receptors are involved in behavioral learning in turtles in a way that is similar to the way in which they function in the mammalian brain. We cannot rule out the possibility, however, that MK-801 disrupted normal synaptic functioning in turtles, rather than disrupting long-term potentiation.

Several studies in mammals have shown that MK-801 disrupts acquisition of a task but not memory for the task once it is learned (Heale \& Harley, 1990). In the present study, the data suggest that all three groups remembered the T-maze learned previously and that the groups did not differ in their memory. These findings suggest that the drug did not produce a memory deficit.
To rule out the possibility that changes in activity were responsible for the differences in performance between groups, various measures of activity in each of the experimental groups were compared. Analysis of these data suggested that the experimental manipulations did not affect the turtles' activity. In the maze, no difference was found between groups in number of alleys entered. Experiment 2 demonstrated no differences in activity in measures of unlearned behavior between turtles given saline or MK-801. In rats, Heale and Harley (1990) found that MK-801 given on 2 successive days caused increased activity on both days, but the difference was larger on the 2nd day. In the present study, no evidence of increased activity with a single dose of the drug was found. Although the data on entries argues against the possibility that cumulative effects were developing (see Figure 3), it would be important to explore further the effects of chronic administration of MK-801 on activity in turtles.

Although motivational changes are another explanation for our results, this explanation is not supported by observations made during the experiment. Every turtle ate the food available when reaching the goal box, and all animals ate well in their home cages, regardless of group membership.

Although the reptilian dorsal cortex seems to function quite similarly to the mammalian hippocampus, evidence to date does not support direct and unqualified comparisons of the two structures (Powers, 1990). Damage to the reptilian dorsal cortex, for example, has produced deficits in the acquisition of a simultaneous visual discrimination task (Blau \& Powers, 1989), whereas damage to the mammalian hippocampus has produced no such impairment (O'Keefe \& Nadel, 1978). Also, the reptilian medial cortex, a structure that is thought to be anatomically analogous to the mammalian hippocampus (Powers, 1990), has not been shown to be involved in learning (Grisham \& Powers, 1989, 1990). Thus although they are similar, the reptilian dorsal cortex and the mammalian hippocampus are not perfectly comparable structures.

Despite these limitations, the present results provide evidence that the dorsal cortex, an area of the turtle brain previously demonstrated as being involved in learning, is specifically involved in learning of a position habit in a maze, and that this learning also is impaired by injections of MK-801. The results thus expand our understanding of brain function in turtles and provide new information about the way in which vertebrate brains mediate learning.

\section{REFERENCES}

Artola, A., \& SingER, W. (1987). Long-term potentiation and NMDA receptors in rat visual cortex. Nature, 330, 649-652.

BlaU, A., \& Powers, A. S. (1989). Discrimination learning in turtles after lesions of the dorsal cortex or basal forebrain. Psychobiology, $17,445-449$.

Bliss, T. V. P., \& LYNCH, M. A. (1988). Long-term potentiation of synaptic transmission in the hippocampus: Properties and mechanisms. In P. W. Landfield \& S. A. Deadwyler (Eds.), Long-term potentiation: From biophysics to behavior (pp. 3-72). New York: Alan R. Liss. 
Collingridge, G. L., \& Bliss, T. V. P. (1987). NMDA receptors their role in long-term potentiation. Trends in Neuroscience, 10 , 288-293.

COtMan, C. W., \& IVERSEN, L. L. (1987). Excitatory amino acids in the brain-focus on NMDA receptors. Trends in Neuroscience, 10, 263-265.

Cranney, J., \& Powers, A. S. (1983). The effects of core nucleus and cortical lesions in turtles on reversal and dimensional shifting. Physiological Psychology, 11, 103-111.

ERrington, M. L., LYNCH, M. A., \& Bliss, T. V. P. (1987). Long-term potentiation in the dentate gyrus: Induction and increased glutamate release are blocked by $\mathrm{D}(-)$ aminophosphonovalerate. Neuroscience, 20, 279-284.

Gilbert, M. E., \& MACK, C. M. (1990). The NMDA antagonist MK801 suppresses long-term potentiation, kindling, and kindlinginduced potentiation in the perforant path of the unanesthetized rat. Brain Research, 519, 89-96.

Grisham, W., \& POWERS, A. S. (1989). Function of the dorsal and medial cortex of turtles in learning. Behavioral Neuroscience, 103 , 991-997.

Grisham, W., \& Powers, A. S. (1990). Effects of dorsal and medial cortex lesions on reversals in turtles. Physiology \& Behavior, 47, 43-49.

HEALE, V., \& HARLEY, C. (1990). MK-801 and AP5 impair acquisition, but not retention, of the Morris milk maze. Pharmacology, Biochemistry \& Behavior, 36, 145-149.

Killackey, H., Pellmar, T., \& Ebner, F. F. (1972). The effects of general cortex ablation on habituation in the turtle. Federation Proceedings, 31, 819

KLEINSCHMIDT, A., BEAR, M. F., \& SINGER, W. (1987). Blockade of "NMDA" receptors disrupts experience-dependent plasticity of kitten striate cortex. Science, 238, 355-357.

LaRSON, J. R., \& LYNCH, G. (1988). Long-term potentiation in lizard cerebral cortex. Society for Neuroscience Abstracts, 14, 777.

Larson-Prior, L. J., \& Slater, N. T. (1988). Barium reveals NMDA receptor-mediated synaptic transmission in turtle hippocampus. Society for Neuroscience Abstracts, 14, 943.

McCabe, B. J., Davey, J. E., \& HoRN, G. (1992). Impairment of learning by localized injection of an $N$-methyl-D-aspartate receptor antagonist into the hyperstriatum ventrale of the domestic chick. Behavioral Neuroscience, 106, 947-953.

Miserendino, M. J., Sananes, C. B., Melia, K. R., \& Davis, M. (1990). Blocking of acquisition but not expression of conditioned fear-potentiated startle by NMDA antagonists in the amygdala. $\mathrm{Na}$ ture, 345, 716-718.

MORLOCK, H. C. (1972). Behavior following ablation of the dorsal cortex of turtles. Brain, Behavior, \& Evolution, 5, 256-263.

Morris, R. G. M., ANDERson, E., LYNCH, G. S., \& BAUdRY, M. (1986). Selective impairment of learning and blockade of long-term poten- tiation by an $\mathrm{N}$-methyl-D-aspartate receptor antagonist, AP5. $\mathrm{Na}$ ture, 319, 774-776.

O'KeEFE, J., \& NADEL, L. (1978). The hippocampus as a cognitive map. Oxford: Oxford University Press, Clarendon Press.

Peterson, E. (1980). Behavioral studies of telencephalic function in reptiles. In S. O. E. Ebbesson (Ed.), Comparative neurology of the telencephalon (pp. 343-388). New York: Plenum.

Petrillo, M., Ritter, C. A., \& Powers, A. S. (1994). A role for acetylcholine in spatial memory in turtles. Physiology \& Behavior, 56, 135-141.

Powers, A. S. (1990). Brain mechanisms of learning in reptiles. In R. P. Kesner \& D. S. Olton (Eds.), Neurobiology of comparative cognition (pp. 157-177). Hillsdale, NJ: Erlbaum.

Powers, A. S., \& ReINer, A. (1980). A stereotaxic atlas of the forebrain and midbrain of the eastern painted turtle. Journal für Hirnforschung, 21, 125-159.

Robinson, G. S., JR., Crooks, G. B., JR., Shinkman, P. G., \& GalLAGHER, M. (1989). Behavioral effects of MK-801 mimic deficits associated with hippocampal damage. Psychobiology, 17, 156-164.

Shapiro, M. L., \& Caramanos, Z. (1990). NMDA antagonist MK-801 impairs acquisition but not performance of spatial working and reference memory. Psychobiology, 18, 231-243.

Shapiro, M. L., \& O'ConNOR, C. (1992). N-methyl-D-aspartate receptor antagonist MK-801 and spatial memory representation: Working memory is impaired in an unfamiliar environment but not in a familiar environment. Behavioral Neuroscience, 106, 604-612.

Tonkiss, J., MorRIS, R. G. M., \& RaWlins, J. N. P. (1988). Intra-ventricular infusion of the NMDA antagonist AP5 impairs performance on a non-spatial operant DRL task in the rat. Experimental Brain Research, 73, 181-188.

Venable, N., \& Kelly, P. H. (1988). Effects of MK-801, an antagonist of the $N$-methyl-D-aspartate type of excitatory amino acid receptor, in two-trial memory tests. Society for Neuroscience Abstracts, 14, 248

Willner, J., Gallagher, M., Graham, P. W., \& Crooks, G. B., Jr. (1992). $N$-methyl-D-aspartate antagonist D-APV selectively disrupts taste-potentiated odor aversion learning. Behavioral Neuroscience, 106, 315-323.

XU, X., \& DAvis, R. E. (1992). $N$-methyl-D-aspartate receptor antagonist MK-801 impairs learning but not memory fixation or expression of classical fear conditioning in goldfish (Carassius auratus). Behavioral Neuroscience, 106, 307-314.

Young, A. B., SAKURAI, S. Y., \& ALBIN, R. L. (1990). [ ${ }^{3}$ H]Glutamate binding in turtle brain. Society for Neuroscience Abstracts, 16, 90.

(Manuscript received August 27, 1993; revision accepted for publication December 5, 1994.) 